\title{
Saint-Père (Yonne), église Saint-Pierre
}

\section{Christian Sapin}

\section{(2) OpenEdition}

\section{Journals}

\section{Édition électronique}

URL : https://journals.openedition.org/cem/893

DOI : 10.4000/cem.893

ISSN : 1954-3093

\section{Éditeur}

Centre d'études médiévales Saint-Germain d'Auxerre

\section{Édition imprimée}

Date de publication : 15 août 2004

ISSN : 1623-5770

\section{Référence électronique}

Christian Sapin, « Saint-Père (Yonne), église Saint-Pierre », Bulletin du centre d'études médiévales d'Auxerre | BUCEMA [En ligne], 8 | 2004, mis en ligne le 13 décembre 2006, consulté le 22 septembre 2022. URL : http://journals.openedition.org/cem/893 ; DOI : https://doi.org/10.4000/cem.893

Ce document a été généré automatiquement le 22 septembre 2022.

\section{(c) (i) (2)(2)}

Creative Commons - Attribution - Pas d'Utilisation Commerciale - Partage dans les Mêmes Conditions 4.0 International - CC BY-NC-SA 4.0

https://creativecommons.org/licenses/by-nc-sa/4.0/ 


\title{
Saint-Père (Yonne), église Saint- Pierre
}

\author{
Christian Sapin
}

1 L'ancienne église Saint-Pierre à Saint-Père, près de Vézelay, située à cent mètres au sud de l'actuelle église paroissiale Notre-Dame construite au XIII ${ }^{e}$ siècle, avait fait l'objet de deux campagnes d'étude de son bâti en 2001-2002. Ces dernières avaient mis en évidence deux phases différentes dans sa construction : une nef unique avec abside et structure occidentale, et au XII ${ }^{\mathrm{e}}$ siècle, l'adoption d'un collatéral au nord. Une campagne de fouilles archéologiques au sol devait permettre, en 2003, de préciser l'organisation, l'occupation et la datation du premier état. Il avait en particulier été remarqué la présence de fragments de sarcophages mérovingiens en réemploi dans cet édifice qui passe, dans la tradition, pour être l'emplacement initial de la fondation carolingienne de Vézelay de 860. Cette année, la fouille d'un secteur limité à l'est allait confirmer l'existence d'une occupation mérovingienne avec un sarcophage en place et de nombreux fragments retrouvés sur le site, situant cette occupation entre le $\mathrm{VI}^{\mathrm{e}}$ et le VIII siècle. Dans le secteur de l'abside, très bouleversé par les inhumations modernes (XVII ${ }^{e_{-}}$ $\mathrm{XIX}^{\mathrm{e}}$ siècles) et par les fouilles sauvages, il n'a pas encore été possible d'identifier avec certitude des états de maçonneries antérieurs au XI ${ }^{e}$ siècle. À l'ouest, au contraire, la présence d'une structure semi-circulaire postérieure à des inhumations et sur laquelle repose le petit massif occidental $\left(\mathrm{X}^{\mathrm{e}}-\mathrm{XI}{ }^{\mathrm{e}} \mathrm{s}\right.$. ?) laisse supposer une pérennité d'occupation. Ce développement à l'endroit où un sarcophage mérovingien (identifié en 1965) a été réutilisé, n'est sans doute pas le fruit du hasard. En conclusion, ces deux secteurs suffisent à justifier une poursuite des opérations à condition que, parallèlement, s'engage un processus de conservation et de restauration des structures menaçant ruine et des peintures de l'abside (début du XIII ${ }^{e}$ siècle ?) qui ont pu être en partie relevées et dessinées. La poursuite des recherches est également nécessaire pour comprendre le statut de ce site au haut Moyen Âge, avant et pendant la période carolingienne. De cette dernière, ont été retrouvés deux fragments de chancels à décor d'entrelacs, qui attestent au moins d'aménagements liturgiques. 


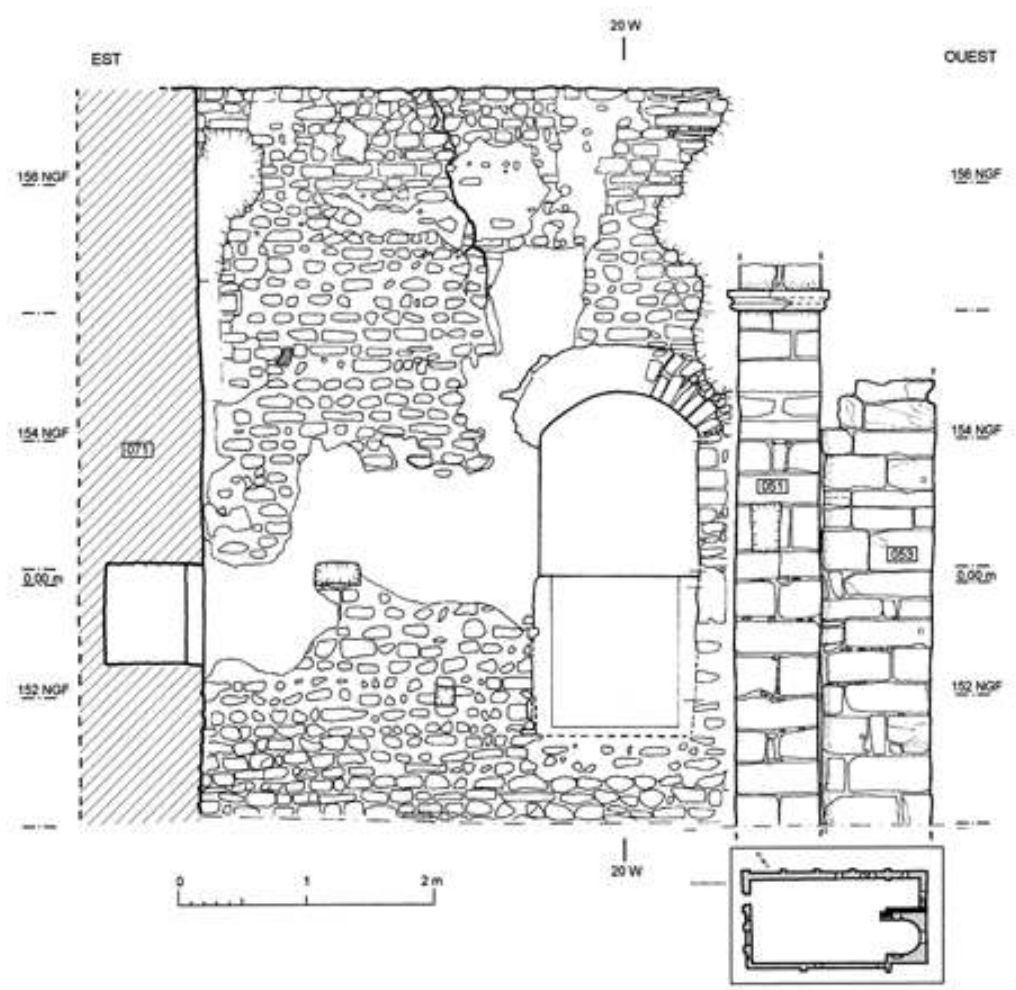

Fig. 1 - Saint-Père, église Saint-Pierre. Chapelle nord-est, mur sud, élévation E/W (CEM).

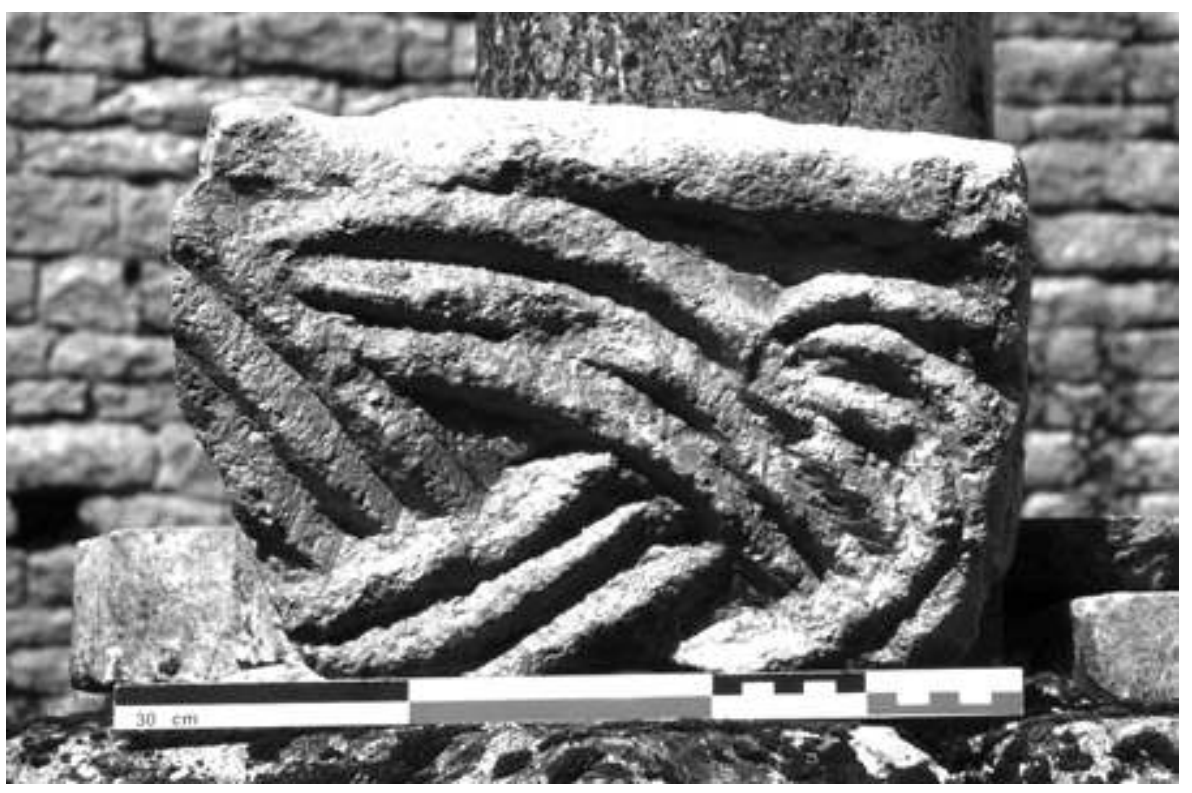

Fig. 2 - Saint-Père, église Saint-Pierre. Fragment de chancel trouvé en remploi (CEM). 
INDEX

Mots-clés : Saint-Pierre de Saint-Père

Index géographique : France/Saint-Père 